\title{
O sentido ético-estético do corpo na cultura popular e a estruturação do campo gestual
}

\author{
Larissa Michelle Lara*
}

\begin{abstract}
Resumo: O texto analisa a construção do sentido éticoestético do corpo na cultura popular, buscando subsídios para reflexões acerca da estruturação do campo gestual. Por meio de incursões teóricas pela Filosofia e Antropologia Social, o conceito de sentido ético-estético foi elaborado, assim como foram extraídas categorias de análise para o entendimento desse sentido na cultura popular a partir de pesquisa do tipo etnográfico. As investigações apontam para um processo de normatização coletiva que gera técnicas corporais próprias às comunidades de cultura popular, as quais se colocam como parte de uma teia complexa de relações.
\end{abstract}

Palavras-chave: Ética. Estética. Corpo. Dança. Diversidade cultural.

\section{INTRODUÇÃO}

O entendimento de que as técnicas do corpo não surgem aleatoriamente, mas são resultantes de um processo normativo construído a partir das relações que o ser humano estabelece, põe em cena o gestual popular. A forma como cada indivíduo age em sociedade não é resultado de ações isoladas, nem tampouco as práticas corporais que elege, mas emerge de um intenso processo normativo, revelador de um sentido que é, ao mesmo tempo, ético e estético, delimitando condutas prático-morais e expressivo-comunicativas próprias da vida coletiva.

Em se tratando de cultura popular, especialmente no que se refere à construção da gestualidade, podem ser observados elementos complexos que perfazem a vida comunitária e que definem,

Doutora pela Faculdade de Educação da Universidade Estadual de Campinas - FE/UNICAMP Docente do Departamento de Educação Física da Universidade Estadual de Maringá - DEF/ UEM. Líder do Grupo de Pesquisa Corpo Cultura e Ludicidade - DEF/UEM. Marília, PR, Brasil. E-mail: Imlara@uem.br. 
sobretudo, seus traços identificatórios. O corpo, na cultura popular, coloca-se para além de sua dimensão técnica ou coreográfica. Revela significados em seu ensejo de transformar, alertar, expressar-se, fazerse ouvido/sentido/percebido em suas lutas e necessidades.

A cultura popular, com base nos estudos de Chauí (1995), é entendida como forma de expressão dos dominados, como manifestação diferenciada que se realiza no interior de uma sociedade que, embora seja a mesma para todos, apresenta-se repleta de sentidos e finalidades diferentes para cada uma das classes sociais. Tal cultura é pensada como:

[...] conjunto disperso de práticas, representações e formas de consciência que possuem lógica própria (o jogo interno de conformismo, do inconformismo e da resistência), distinguindo-se da cultura dominante exatamente por essa lógica de práticas, representações e formas de consciência. (CHAUÍ, 1995, p. 25).

É por esse viés que a cultura popular, valorizada, sobretudo, por seu campo gestual, será abordada neste estudo.

Parto do pressuposto de que o gesto dançante observado de modo isolado da vida coletiva não dá conta do entendimento da cultura popular. A utilização de danças para fins educacionais somente pelo aprendizado das técnicas corporais ${ }^{1}$ próprias de uma dada manifestação popular representa não apenas a fragmentação do conhecimento, mas seu engessamento, desconsiderando a lógica interna de consciência das comunidades populares, bem como seu jogo dinâmico de conformismo e resistência. Tal constatação tornase essencial a uma intervenção pedagógica, pois questiona a forma instrumental como a cultura popular é tratada. A falta de conhecimento, de pesquisa, de entendimento do homem para além de sua dimensão naturalizada, atrelado à simplificação dos saberes

\footnotetext{
${ }^{1} \mathrm{O}$ antropólogo Marcel Mauss é reconhecido como o primeiro a ver nas técnicas corporais uma forma de manifestação cultural e a inaugurar uma discussão até então inédita em torno do corpo e do gesto. Cf. MAUSS, Marcel. Sociologia e antropologia. São Paulo: EPU: 1974.

Movimento, Porto Alegre, v. 13, n. 03, p. 111-129, setembro/dezembro de 2007.
} 
e à sua funcionalidade, conduz ao desvencilhamento do campo gestual de seu conjunto, de sua totalidade.

A identificação de uma manifestação cultural como sendo um maracatu, um coco, um frevo ou um bumba-meu-boi dá-se não apenas pelo movimento, mas por um conjunto de elementos que o constituem, a exemplo dos ritmos produzidos, das letras entoadas, das vestimentas características e da expressão simbólica. Além do mais, a forma como o gestual popular é delineado está, sobretudo, relacionado à produção histórico-cultural da comunidade (seus ritos, sua religiosidade, sua forma de se relacionar com o antigo e o novo, suas construções normativas ético-estéticas para convivência em grupo e para o desenvolvimento de dada manifestação cultural).

Partindo da análise da construção do sentido ético-estético do corpo na cultura popular e buscando subsídios para viabilizar reflexões acerca das relações dialógicas entre ética e estética na estruturação do campo gestual é que este estudo foi delineado. Tal investigação deu-se a partir de incursões teóricas pela Filosofia e Antropologia Social, bem como pelo contato com uma comunidade de maracatu nação ${ }^{2}$ a partir do desenvolvimento de estudo do tipo etnográfico em Recife (PE). O presente artigo explora as categorias de análise extraídas dessa pesquisa, não objetivando a descrição pormenorizada dos dados coletados. Isso pelo fato de o enfoque não estar na manifestação do maracatu (embora tenha sido a manifestação elegida para coleta), mas na organização coletiva de um dado grupo popular a partir das relações ético-estéticas que estabelece. É esse o recorte que o estudo se propõe a fazer.

\footnotetext{
${ }^{2} \mathrm{O}$ maracatu nação é uma manifestação da cultura popular afro-brasileira representada por um cortejo real que envolve música, dança, toadas, personagens (reis, rainhas, príncipes, princesas, damas do paço, calunga), rituais preparatórios e outros. Sua origem estaria nas antigas coroações de reis e rainhas africanos, realizadas pelos negros no Brasil, e que contavam com a proteção do "senhor branco" e o consentimento da Igreja Católica, numa forma de controle social. Essas festas deixam de ser toleradas ou aceitas com a Abolição da Escravatura e a Proclamação da República, uma vez que passam a ser vistas como coisa de negro. A esse respeito, cf. ANDRADE, Mário de. Danças dramáticas do Brasil. São Paulo: Itatiaia, 1982. PEIXE, Guerra. Maracatus do Recife. São Paulo, Rio de Janeiro: Irmãos Vitali, 1980
}

Wovimento, Porto Alegre, v. 13, n. 03, p. 111-129, setembro/dezembro de 2007. 
O texto em questão encontra-se organizado em duas etapas: a) reflexão sobre a construção do sentido ético-estético do corpo; b) entendimento do corpo ético-estético na cultura popular, tomando por elemento investigativo: o maracatu. Tal manifestação cultural é percebida como possibilidade de reconhecimento do popular e de seu sentido ético-estético a partir da imersão numa realidade local. É o ingresso na comunidade de maracatu por meio do processo dialético de estranhamento/familiarização que possibilitou a extração de categorias de análise para as reflexões que ora seguem.

As investigações consideram, sobretudo, as teias relacionais que envolvem a estruturação do campo gestual, reveladas pela construção cultural do corpo, pelas regras, princípios e processos normativos que organizam a vida em comunidade. É nesse sentido que o estudo visa trazer contribuições à elucidação do corpo em sua dimensão ético-estético e à construção do campo gestual a partir da complexidade que perfaz a vida comunitária, potencializando outros sentidos à educação.

\section{O CORPO POPULAR... ÉTICO, ESTÉTICO}

Ao realizar incursões teóricas pela Filosofia no intuito de perceber como se deram as relações históricas entre ética e estética, o conceito de sentido ético-estético foi construído. ${ }^{3}$ Foram observadas relações de dependência entre ética e estética a partir das categorias de bem, bom, belo e divino (da filosofia antiga à renascentista), bem como rupturas nessa dependência (da filosofia moderna à contemporânea), especialmente quando arte, estética, moral e ética já não se colocam mais atrelados à idéia de bem e belo. ${ }^{4}$

\footnotetext{
${ }^{3} \mathrm{O}$ entendimento histórico das relações entre ética e estética pode ser conferido em LARA, Larissa Michelle. $\mathbf{O}$ sentido ético-estético do corpo na cultura popular. Tese (Doutorado em Educação) - Faculdade de Educação, UNICAMP, Campinas, 2004.

${ }_{4}^{4}$ Tomo por base a classificação dos períodos da filosofia apresentada por Marilena Chauí: filosofia antiga (VI a.C. a VI d.C.), filosofia patrística (I a VII), filosofia medieval (VIII a XIV), filosofia da Renascença (XIV a XVI), filosofia moderna (XVII a meados de XVIII), filosofia da Ilustração (meados de XVIII a início de XIX) e filosofia contemporânea (meados de XIX aos nossos dias). Cf. CHAUÍ, Marilena. Convite à filosofia. 12. ed. São Paulo: Ática, 2001.
}

Movimento, Porto Alegre, v. 13, n. 03, p. 111-129, setembro/dezembro de 2007. 
A necessidade de estruturação de um conceito de sentido éticoestético que levasse em conta o ser humano em sua dimensão sensível/racional levou-me ao entendimento da ética como filosofia moral que lida com investigações acerca de regras e valores mais gerais, norteando as ações humanas e sendo guiada por princípios racionais ligados à realidade histórico-cultural. Por sua vez, a estética foi visualizada como teoria filosófica das formas de manifestação do sensível, do belo, do feio, do gosto, do trágico, da arte, por meio de leis, padrões e regras que regem suas relações com o humano. Daí as interações entre ética e estética a partir de seu processo normativo para delinear o conceito de sentido ético-estético.

Mesmo tendo sido concretizado diferentemente ao longo da história da Filosofia, seja pela predominância da razão e do belo em detrimento do sensível, do feio e do grotesco, ou ainda pela tentativa de conciliá-los, as formas de manifestação do sentido ético-estético na sociedade contemporânea ainda perpassam esses caminhos, embora haja, atualmente, tentativas concretas de pensar um homem marcado por suas tensões apolíneas/dionisíacas, racionais/sensíveis, belas/feias, sérias/cômicas, expressas nos escritos de filósofos, educadores, antropólogos, artistas e outros.

O sentido ético-estético discutido neste texto é entendido como dimensão humana que traduz a forma do homem ser, agir e sentir em suas relações sociais, marcada por sua racionalidade, sensibilidade e capacidade criadora, disciplinada ou transgressora. É o que representa a possibilidade de pensar as ações do homem nas relações que estabelece com as outras pessoas e com o mundo, resultado de um processo coletivo e normativo de construção das regras sociais que se dá pelo entendimento de si como produto e produtor de cultura.

Esse sentido, expresso no corpo e em seu processo normativo, revela-se a partir dos paradoxos humanos. Foge da associação do bem ao belo, como na filosofia socrático-platônica, e também do belo e do bem atrelados a Deus, a exemplo da filosofia medieval. Ruma em direção ao entendimento normativo a partir das contradições próprias do ser social. Daí ser uma categoria essencial para se pensar o humano, bem como para refletir a estruturação do campo gestual em comunidades populares.

Movimento, Porto Alegre, v. 13, n. 03, p. 111-129, setembro/dezembro de 2007. 
O corpo que dança na cultura popular é orientado por técnicas próprias de uma dada comunidade de acordo com os valores, as normas e as tradições que elege, sendo estas não diretamente atreladas à indústria cultural, ${ }^{5}$ embora nem sempre alijadas de suas seduções. A gestualidade própria de determinada dança da cultura popular congrega uma dimensão ético-estética delineadora da coletividade, pois expressa não o movimento em si, mas suas formas comunicativas reveladoras e seus conteúdos de denúncia, apelo, ajuda, arte.

As técnicas corporais - técnicas próprias do corpo, em seu gestual comunicativo, estético/expressivo e normativo, resultantes dos elos culturais estabelecidos em sociedade - revelam-se de formas diferenciadas a partir de como cada comunidade de cultura popular as concebem. Associadas às formas cotidiana, profana, sagrada, laboral, ociosa, lúdica, instintiva e/ou criativa, as técnicas corporais traduzem aquilo que não se vê diretamente, mas que está imbricado no gestual popular, em sua capacidade de potencializar uma comunicação intersubjetiva que extrapole individualidades rumo ao diálogo libertador.

O processo de mundialização cultural, ${ }^{6}$ acrescido dos meios midiáticos, fez com que as fronteiras que delimitavam as técnicas corporais passassem a ser rompidas ou, pelo menos, flexibilizadas. Talvez, ainda, deturpadas, como se uma única parte fosse capaz de representar o todo, embora acreditando que essa parte o constituísse e o representasse. Um exemplo está no Brasil, visto por outras culturas como lugar privilegiado do futebol e do carnaval, bem como da pobreza e violência nas favelas. As imagens da licenciosidade do brasileiro, do corpo nu e vendável, das mulatas e da "guerra declarada" são uma espécie de fotografia de nossa identidade, incompleta se

\footnotetext{
${ }^{5} \mathrm{O}$ termo "indústria cultural" é utilizado com base em Adorno e Horkheimer e refere-se ao sistema que busca homogeneizar por meio de técnicas de poder dos economicamente mais fortes, tendo a venda de produtos culturais como meio de sedução e formação de um sensocomum cristalizado. ADORNO, Theodor; HORKHEIMER, Max. Dialética do esclarecimento. Rio de Janeiro: Jorge Zahar, 1985.

${ }^{6}$ O termo "mundialização cultural" refere-se ao processo de hibridização cultural que transcende espaços geográficos, fazendo com que as diferentes culturas se misturem, se acrescentem e se diversifiquem por meio das relações sociais que estabelecem. Cf. ORTIZ, Renato. Mundialização e cultura. São Paulo: Brasiliense, 2000.
}

Mvimento, Porto Alegre, v. 13, n. 03, p. 111-129, setembro/dezembro de 2007. 
pensarmos em outras tantas caracterizações que poderíamos atribuir. Isso porque a cultura brasileira consolida-se pela diversidade, por uma cultura do corpo ampla e esteticamente multifacetada, resultante de aculturações que envolvem o branco, o negro e o índio.

No dizer de Chauí (1995), toda cultura institui uma moral que transita entre o bem e o mal, o permitido e o proibido, o correto e o incorreto, válida para todos os seus membros. Contudo, várias morais podem ser estabelecidas em sociedades e culturas fortemente hierarquizadas, com diferenças profundas de castas e classes sociais. Tal idéia reforça a proposição esboçada de que as comunidades que se formam e congregam determinada representação cultural instituem morais, condutas que sejam válidas para o grupo. Mas, os valores concernentes ao que seja correto não partem única e exclusivamente de uma singularidade do grupo, mas obedecem a uma moral universalizante em sua essência, ou seja, valores que toquem virtudes como justiça, amizade e respeito.

Se observarmos uma comunidade popular ou comunidades que se organizam a partir de objetivos comuns, percebemos que vários dos conhecimentos adquiridos são passados de geração a geração, transmitidos em grande parte de forma oral, mantendo uma função social e persistindo ao longo de anos. Contudo, a existência da moral não indica a presença explícita da ética, ou seja, de uma filosofia moral, o que leva a problematizações e interpretações do significado dos valores morais. Nem tampouco podemos afirmar, segundo Chauí (1995), que os valores morais sejam idênticos aos fatos constatáveis na vida cotidiana, ou seja, que a forma como uma comunidade age na atualidade é correta porque os antepassados a realizavam.

Embora sentimentos, condutas, ações e comportamentos sejam modelados por atos políticos, educacionais, religiosos, familiares, não se pode simplesmente reproduzir os valores propostos pela sociedade e tomá-los como modelos exemplares. Assim, qual o sentido dos costumes, ou ainda, que características pessoais e condutas individuais levam alguém a respeitar ou transgredir valores concernentes a uma comunidade e por quê?

Ao me voltar para o campo da cultura popular brasileira procuro, a todo instante, (re)construir cenários e personagens que fazem parte

Movimento, Porto Alegre, v. 13, n. 03, p. 111-129, setembro/dezembro de 2007. 
de várias histórias. Entre formas gestuais, cotidiano, experiência estética, vivência das regras sociais e de convivência em grupo, almejo caminhos que me conduzam a um desvelar de imagens. Seja pelo rufar das alfaias dos maracatus nação, pelo corpo extásico ao som do bumba-meu-boi, pelo ritmo tribal dos maracatus rurais, pelo estalido das preacas dos caboclinhos, dentre outras manifestações culturais populares, ${ }^{7}$ o sentido ético-estético do corpo vai sendo construído. Identifico similaridades entre os populares, expressas na forma como se organizam coletivamente, no respeito às regras sociais e na vivência do comportamento mítico. ${ }^{8}$

Os signos corporais estão intimamente ligados à construção cultural de cada sociedade. Embora as falas tragam os regionalismos, assim como as expressões próprias de cada comunidade, é pela comunicação não-verbal que as especificidades corpóreas são reconhecidas. As normatizações expressas em dado grupo de cultura popular estão intimamente ligadas às influências formadoras da sociedade. O corpo reflete tais influências e as concretiza.

As técnicas corporais próprias das comunidades populares nos levam a identificar e diferenciar um maracatu rural de um caboclinho e um bumba-meu-boi justamente pela pluralidade cultural resultante de intercâmbios/fusões raciais que se dão de diferentes formas a partir do processo criativo que perpassa as comunidades. Essas técnicas corporais, assim como a forma de realização de dada manifestação, são históricas e, portanto, carregam consigo os desejos da coletividade. É por isso que as novas necessidades morais dos grupos podem conduzir a mudanças na realização das manifestações no que diz respeito a personagens, vestimentas, instrumentais, assim como a sua estética pode originar mudanças conceituais na vida coletiva. Geralmente, essas necessidades morais e estéticas estão

\footnotetext{
${ }^{7}$ Manifestações culturais populares como maracatu nação, maracatu rural, bumba-meu-boi, caboclinhos, e outras, podem ser observadas em CASCUDO, Luís da Câmara. Dicionário do folclore brasileiro. 10. ed. São Paulo: Global, 2001. Cf. também ANDRADE, Mário de. Danças dramáticas do Brasil. São Paulo: Itatiaia, 1982.

${ }^{8}$ Sobre comportamento mítico como imitação de um modelo trans-humano, repetição de um cenário exemplar e ruptura do tempo profano, cf. ELIADE, Mircea. Mitos, sonhos e mistérios. Lisboa: Ed. 70, 1989.
}

Mvimento, Porto Alegre, v. 13, n. 03, p. 111-129, setembro/dezembro de 2007. 
permeadas de sentido mítico, religioso, de devoção, de crença, como se dá com o caboclo de lança no maracatu rural que dança atuado, com o feiticeiro da floresta no bumba-meu-boi, com os caboclinhos que pedem proteção a seus atos guerreiros, ou com a dama-dopaço no maracatu nação ao levar consigo a boneca calunga. ${ }^{9}$

Por quê a movimentação garbosa, requintada de homens e mulheres nas danças gaúchas, com suas roupas luxuosas e ausentes de decotes ou mostra de pernas? Por quê a sensualidade de um carimbó ou lundu marajoara, expressa no corpo que dança, no remelexo de quadril, nos ombros e umbigos à mostra? De onde vem a normatização de um sapateado exclusivamente masculino nas danças de fandango paranaense, assim como a caracterização caiçara e suas sutis aproximações corporais? Que força brota de um frevo, de um coco e de um maracatu recifense? O que nos instiga a capoeira baiana?

É certo que a delimitação do sentido ético-estético dessas manifestações populares, do corpo que as realiza, não foi imposta por mecanismos legais. Os valores concernentes a cada manifestação foram se consolidando e se transformando em conhecimento passado de geração a geração, sob efeito das mudanças próprias à dinamicidade social. A presença do negro nos canaviais da região nordeste contribuiu para originar um tipo de cultura diferenciada, por exemplo, da região sul, que recebe seus contornos da imigração européia e asiática, o que leva a pensar na influência colonizadora que se repercute fortemente nas manifestações gestuais desses povos.

Ingressando mais diretamente no mundo dos populares, pergunto: Que racionalidade leva a identificar uma manifestação como sendo cultura popular? Como se configura o sentido ético-estético do corpo nas manifestações populares? Como se consolida a cultura do corpo? A inserção numa comunidade de cultura popular auxilia a pensar essas questões.

\footnotetext{
${ }^{9}$ Entre os populares de maracatu nação, a calunga é comumente vista como símbolo mítico na figura de egun (ancestral - rei ou rainha) ou orixás do candomblé, sujeita a rituais de purificação para as saídas durante o carnaval. É quem, ainda, purifica o tempo-espaço da festa para que o cortejo possa passar.

Wovimento, Porto Alegre, v. 13, n. 03, p. 111-129, setembro/dezembro de 2007.
} 


\section{A CONSTRUÇÃO GESTUAL: UM POUCO DO MARACATU}

O contato com a realidade do Maracatu Nação Cambinda Estrela em Recife (PE), no ano de 2001, na localidade de Chão de Estrelas, atenta para a percepção de que a análise do movimento em si não dá conta de entender o sentido ético-estético do corpo na cultura popular. Tal constatação, advinda de pesquisa do tipo etnográfico realizada a partir das técnicas de observação participante e entrevista intensiva, reforçou a necessidade de análise de um dado fenômeno considerando suas teias relacionais. ${ }^{10}$

As informações coletadas a partir da observação em Recife foram agrupadas em quatro eixos: bairro Campina do Barreto e localidade de Chão de Estrelas (centros comerciais, espaços de cultura, educação e lazer, residências, localização do maracatu nação); comunidade pesquisada (cotidiano, ligação com o maracatu); maracatu Cambinda Estrela (organização, características, história, brincantes, gestualidade); período pré-carnavalesco e carnavalesco.

A técnica de entrevista intensiva contou com a participação de dezesseis populares, sendo onze da comunidade de Chão de Estrelas, quatro de outras comunidades e maracatus, e um informante que não convive em coletividades de maracatu, cumprindo a função de pesquisador de cultura popular. Os populares foram informados sobre a pesquisa e, a partir de seu consentimento, os dados passaram a ser coletados. As questões realizadas focaram a vida de cada entrevistado e sua relação com o maracatu, sendo que as demais indagações emergiram do processo dialógico. Os dados resultantes de entrevista resultaram na biografia dos informantes, no entendimento da origem e desenvolvimento do maracatu Cambinda Estrela e no sentido/significado desse maracatu para a comunidade. ${ }^{11}$ Sirvo-me de referenciais

\footnotetext{
${ }^{10}$ Cf. LARA, Larissa Michelle. O sentido ético-estético do corpo na cultura popular. Tese (Doutorado em Educação), Faculdade de Educação, UNICAMP, Campinas, 2004.

${ }^{11}$ Como forma de complementar as informações coletadas, estabeleço territórios - pessoas e lugares - sendo eles: Museu do Homem do Nordeste, Secretaria de Planejamento, Urbanismo e Meio Ambiente da Prefeitura do Recife, Fundação Joaquim Nabuco, Universidade Federal de Pernambuco e o pesquisador Roberto Benjamin. Outros territórios foram os maracatus Nação Elefante, Leão Coroado e Encanto da Alegria.
}

Mvimento, Porto Alegre, v. 13, n. 03, p. 111-129, setembro/dezembro de 2007. 
teóricos como André (1995) e Bogdan e Biklen (1994) para a condução do estudo do tipo etnográfico.

As informações coletadas foram organizadas em eixos norteadores por meio de redução e ordenação do conteúdo síntese dos conhecimentos obtidos por observação, entrevista e documentos analisados. Após essas descrições, as informações foram transformadas em categorias de análise, quando se buscou a interpretação dos dados e sua interlocução com a literatura. É esse o recorte que o texto em questão objetiva com vistas à percepção de como o sentido ético-estético do corpo se dá numa comunidade de cultura popular, o que buscarei esclarecer.

Mesmo não visando a descrição de todos os recortes possíveis da pesquisa, como, por exemplo, os eixos elegidos para observação, a utilização das falas dos populares, os territórios investigados, o que demandaria um outro estudo, cabe fazer algumas elucidações acerca da comunidade pesquisada.

O Maracatu Nação Cambinda Estrela surge no ano de 1935, no Alto de Santa Isabel, bairro de Casa Amarela, na cidade do Recife. Inicialmente, era maracatu de baque solto, mudando o baque em 1953 para atender às pressões da Federação Carnavalesca de Pernambuco. ${ }^{12}$ Os populares vivem em meio à pobreza, ao analfabetismo e à criminalidade. O bairro Campina do Barreto e a localidade de Chão de Estrelas, praticamente unidos, são bastante carentes. Apresentam posto de saúde, centro de cultura (ensino de danças, artesanato e música), escola, praça, campo de futebol, bares, padaria comunitária, entre outros. O lixo cotidiano ganha destaque nas ruas, agravado com as freqüentes enchentes que inundam casas e causam transtorno à população.

Muitos populares do maracatu passam fome, haja vista que as funções de babalorixá (pai-de-santo no candomblé), adestrador de

\footnotetext{
${ }^{12}$ Baque solto é sinônimo de maracatu rural e baque virado, de maracatu nação. A diferença não está apenas na forma de segurar a baqueta para a percussão nos tambores, mas na caracterização gestual, instrumental, histórica e de sentido/significado. Cf. BORBA, Alfredo et al. Brincantes. Recife: Fundação de Cultura Cidade do Recife, 2000. (Coleção Malungo; v. 3).

Movimento, Porto Alegre, v. 13, n. 03, p. 111-129, setembro/dezembro de 2007.
} 
cães, trabalhador em fábrica de salgadinho, estudante, puxador de carroça de papel e de lata, professor e lavadeira não trariam condições financeiras dignas. Para alguns dos populares, maracatu é vida, cultura, forma de luta; para outros, farsa, negócio, meio de sobrevivência. Isso porque há quem indique mau uso dos recursos adquiridos para a comunidade em benefício próprio.

O Candomblé e a Jurema ${ }^{13}$ dão sustentação religiosa à comunidade de maracatu, haja vista que muitos papéis sociais dependem de um envolvimento direto com a religião, assim como as saídas públicas para apresentações, sobretudo no período carnavalesco, momento de valorização da tradição dessa manifestação cultural. É quando os grupos recebem apoio financeiro da Prefeitura por suas apresentações na festa pré-carnavalesca e carnavalesca, bem como recursos advindos de outras fontes, como empresas privadas e ONGs. É o momento mais esperado para a celebração da comunidade e para reivindicação de seus anseios, para expressar suas lutas, seus conformismos e resistências.

É o envolvimento com esse estudo do tipo etnográfico e a realização das investigações teóricas que possibilitaram a organização de sete categorias de análise. A primeira delas diz respeito ao entendimento do "corpo como construção cultural". Por mais que os populares possam ter uma predisposição inata para o gestual dançante, é pela aquisição cultural que efetivamente se instaura o elo com diversas manifestações, seja pela linguagem verbal ou não-verbal. É pela regra, no dizer de Lévi-Strauss (1982), que se pode ter certeza da existência da cultura, assim como é pela característica constante e universal presente nos homens que se manifesta a natureza.

A segunda categoria, em consonância com a primeira, apresenta a idéia de que o "corpo que dança o faz seguindo normatizações

\footnotetext{
${ }^{13}$ Candomblé e Jurema são religiões bastante comuns na cidade do Recife. O candomblé é mais conhecido por Xangô, cujos orixás, na figura humana dos filhos e filhas-de-santo, contribuem para reviver o tempo mítico africano. A Jurema mescla elementos dos cultos afro-brasileiros, como a Umbanda e alguns ritos indígenas. É também o nome de uma árvore. Em Recife, muitos maracatus nação fazem menção ao Xangô e à Jurema, dado que grande número de brincantes integra estas manifestações religiosas.
}

Movimento, Porto Alegre, v. 13, n. 03, p. 111-129, setembro/dezembro de 2007. 
coletivas" instauradas a partir da vivência dos indivíduos em uma dada comunidade, expressas no acordo coletivo de como se conduzir no tempo-espaço da festa, de como realizar o gestual dançante, de como se vestir, de como agir na localidade ou bairro, de como se preparar ritualisticamente para a vivência corpórea. Reforça a idéia de que o corpo, na expressão popular do maracatu, não é mero apêndice, mas foco de simbologias, de representações, de sentido/ significado; que o movimento não é apenas mecanismo de contração/ relaxamento muscular, mas a concretização do fazer ético e estético historicamente situado (individual/coletivo, único/multifacetado).

Há uma moralidade e uma estética construídas historicamente numa comunidade, sendo imitadas e transmitidas por seus membros, mas também repensadas e (re)significadas no contexto da coletividade. Essa terceira categoria reforça a idéia de uma cultura que é viva, flexível e passível de modificações; de uma concretização folclórica que, por mais que busque suas raízes, foge a qualquer tentativa de aprisionamento, embora ceda aos encantos da indústria cultural, da Federação Carnavalesca e de necessidades coletivas mutáveis com o tempo.

A quarta categoria edifica a compreensão da existência de técnicas corporais específicas a cada manifestação cultural e comunidade. Há técnicas próprias para o maracatu nação e para o maracatu rural, para os caboclinhos e para o bumba-meu-boi, para o frevo e para a folia de reis, ou seja, para cada representação cultural, assim como há técnicas corporais diferenciadas dentro de uma mesma manifestação. Por mais que vários grupos populares façam gestualmente uma mesma expressão cultural - o maracatu, por exemplo - apresentando similaridades entre si, técnicas específicas de representação gestual são criadas e marcadas por uma normatização própria.

As novas configurações estéticas surgidas do fazer coletivo dos populares conduzem a mudanças nos padrões morais da comunidade, assim como as configurações éticas influenciam diretamente os contornos estéticos do corpo, idéia que delineia a quinta categoria a ser considerada. Por mais que, antigamente, não

Wovimento, Porto Alegre, v. 13, n. 03, p. 111-129, setembro/dezembro de 2007. 
fossem aceitas mulheres no batuque dos maracatus, que rainhas e damas-do-paço tivessem que ser membros da religião dos candomblés ou xangôs, que homossexuais não pudessem se vestir de mulher, ${ }^{14}$ as necessidades advindas de outras configurações do pensamento ou de problemas originados junto ao grupo (carência de componentes envolvidos com a religião afro-brasileira, luta por inclusão social dos marginalizados, desejo de inovação e poder) conduzem a mudanças estéticas que, gradativamente, passam a ser aceitas e interiorizadas por seus componentes, transformando-se em regras de convivência coletiva.

A sexta categoria atenta para o regime de competição a que se submetem os maracatus, entendendo que as relações competitivas influenciam a construção do sentido ético-estético do corpo na cultura popular. Muitos grupos populares sofrem modificações em função de normatizações impostas por setores externos, como por exemplo, as entidades organizadoras do carnaval, e que envolvem regras para a participação nos desfiles, número de integrantes, exigência de personagens específicos, número de instrumentais e outros. As regras buscam "uniformizar" os gostos, as representações populares, e se concretizam por formas sutis de exercício do poder, embora nem todos se dêem conta da coação que busca homogeneizar para dominar.

A última categoria mostra que as crenças religiosas determinam a configuração ritualística das manifestações populares e influenciam o delineamento do sentido ético-estético do corpo. Como esclarece Durkheim (1989, p. 72), “[...] as crenças religiosas são representações que exprimem a natureza das coisas sagradas e as relações que essas mantêm entre si e com as coisas profanas". A relação dos homens com o sagrado, ou seja, com aquilo que os interditos protegem e isolam, dá-se a partir de ritos que atuam como regras de comportamento, prescrevendo como eles devem agir. O sentido ético-estético do corpo concretiza-se pela crença em seres, espíritos ou deuses que atuam dando respostas e auxiliando a comunidade, o

${ }^{14}$ Tais aspectos, hoje, não são referência em todos os maracatus, sendo que alguns fazem questão de preservar normatizações antigas.

Movimento, Porto Alegre, v. 13, n. 03, p. 111-129, setembro/dezembro de 2007. 
que nem sempre é possível de ser concretizado nas ações dos políticos. Por meio da dança, ficam suspensos a fome, o cansaço, as dores e a miséria, instaurando-se um momento mítico único, possível de ser observado, também, em outras expressões populares.

Mesmo que as tradições tendam a ser preservadas, as mudanças são visíveis a partir de outras necessidades presentes em gerações que vivem contextos diversos. Há sempre novas regras de convivência postas aos populares, ou criadas por eles, marcadas por diferentes tecnologias, governos, relações familiares, educacionais e outras. Mudam-se, portanto, as estéticas gestuais por meio da moralidade em vigor, assim como a necessidade de incluir novos gestuais, pessoas e coisas conduzem ao estabelecimento de outros comportamentos. É um jogo dialético, de influências mútuas, de relações recíprocas que se dão no cotidiano, nas festas, no trabalho e na religiosidade.

Esse sentido ético-estético expresso no corpo, no gestual dançante, identifica a cultura de uma comunidade, a normatização que a leva a se expressar daquela maneira e não de outra, sob determinadas condições. É o corpo o mecanismo do acontecer simbólico, religioso e festivo. É ele, como construção cultural, que torna possibilitada a relação com os outros seres humanos e que retira a aridez do mundo das sociedades pela instauração de um novo tempoespaço. É ele, racional, sensível e comunicativo, que possibilita o fluir de uma nova ordem, do acontecer dialógico ético-estético.

\section{CONSIDERAÇÕES FINAIS}

A análise do sentido ético-estético do corpo que possibilite a estruturação do campo gestual em comunidades populares somente pôde ser concretizada porque outras demarcações foram traçadas como forma de cercá-lo em sua complexidade. As teorias que conduziram a essas discussões foram guiadas por uma questão problematizadora fundamental: como se dá a construção do sentido ético-estético do corpo na cultura popular? Tal inquietação levoume a um campo diverso e sedutor a partir do contato com a ética, a

Movimento, Porto Alegre, v. 13, n. 03, p. 111-129, setembro/dezembro de 2007. 
estética, a gestualidade e a cultura popular. E, nesse momento, as informações resultantes dessa aventura investigativa brotam como novos desafios postos à educação.

A investigação de como o sentido ético-estético é construído no contexto contemporâneo torna-se possível porque já se reconhece que o homem é resultado da interação natureza/cultura e não apenas produto de Deus e agente de suas vontades. Esse enfoque levou ao entendimento de que as regras, os princípios, as tradições e as técnicas corporais não são imposições divinas postas como destino irremediável, mas construções que têm o homem como agente central.

Foi visando a identificação de normas, leis, princípios, valores que levam uma determinada comunidade a se manifestar gestualmente por meio da dança que busquei desenvolver o estudo. $\mathrm{Ou}$ seja, procurei investigar a construção do sentido ético-estético do corpo, buscando subsídios que viabilizassem reflexões acerca das relações dialógicas entre ética e estética para o entendimento da estruturação do campo gestual popular. Tal intento se fez possível pela compreensão das relações entre ética e estética e pelo processo de constituição da gestualidade em comunidades populares, tomando por base o maracatu nação.

A investigação junto aos populares levou à percepção de que a construção do sentido ético-estético do corpo na estruturação do campo gestual não se dá de forma isolada, mas depende de inúmeras relações próprias da vida comunitária. Ocorre por meio de regras de comportamento da comunidade que definem técnicas corporais e moralidade, aceitas, interiorizadas e veiculadas pela prática cotidiana, modificadas frente a novos contextos, necessidades e coação a que estão submetidos; pelos princípios e valores que definem o que é correto, justo e adequado ao membro de uma comunidade e integrante de manifestação popular, envolvendo, sobretudo, justiça, honestidade, compromisso com o coletivo, respeito; pelo sentido de existência coletiva, preservação das tradições e religiosidade; pelas regras de competição e que influenciam a caracterização das manifestações populares; pelo jogo de conformismo e resistência que leva os indivíduos a cederem aos encantos da indústria cultural, da produção

Movimento, Porto Alegre, v. 13, n. 03, p. 111-129, setembro/dezembro de 2007. 
artística e turística, colocando-se como produto a ser oferecido (e remunerado), embora entendendo que estes mecanismos são os meios de que dispõem para manter viva uma dada expressão popular; pela dinamicidade cultural da comunidade e compreensão de uma historicidade mutável que leva tanto à necessidade de incorporar personagens, instrumentais, vestimentas, gestuais, gerando regras de comportamento até então não estabelecidas, quanto à superação destas regras, conduzindo a outras possibilidades de vivências estéticas.

Essa construção ético-estética ocorre, ainda, pela necessidade de reconhecimento, valorização e registro da existência humana como ser potencial, passando dos dramas populares às luzes do palco, de artista anônimo a artista célebre; por uma necessidade educacional, de conhecimento do homem, do corpo, da gestualidade, do misticismo, da religiosidade, da cura, da organização coletiva e das festas, mas também dos problemas sociais que levam os populares a uma vida de pobreza, de falta de trabalho, de dificuldades de existência; pelo acontecer educacional em sentido amplo, como fenômeno social não restrito aos sistemas formais e como processo de formação cultural pautado na necessidade de autonomia e emancipação.

Vejo, nessas investigações, a possibilidade de repensar o trato pedagógico do campo gestual popular, transcendendo a abordagem meramente técnica do "movimento". Atento para a carência da cultura popular na escola não em seu caráter instrumental, de ensino do gesto desprovido de seu contexto e apenas em momentos festivos, mas disseminadas em sua estrutura complexa - religiosa, lúdica, laboral, coletiva, normativa e outras. Focalizo, ainda, que o trato da cultura popular no sistema escolar, numa dimensão totalizante, seja visto como forma de "resistência" a uma educação que tenha no "erudito" o único meio de conhecimento, potencializando olhares para o que não cabe na racionalidade ocidental. Refiro-me à necessidade de olhar para o "outro da razão", ou seja, para aquilo que é posto à margem da racionalidade ocidental, como a cultura popular, as práticas corporais, o corpo, justamente por sua lógica própria. Repensar essas questões a partir de um processo intercomunicativo

Wovimento, Porto Alegre, v. 13, n. 03, p. 111-129, setembro/dezembro de 2007. 
que gere intervenções no sistema educacional constitui ação fecunda - caleidoscópios que se abrem às percepções humanas.

\begin{abstract}
Ethic-esthetic body sense in the popular culture and the gestual field structure

Abstract: The text analyses the construction of the body ethic-esthetic sense in popular culture, searching for subsides to reflections concerning the gestual field structure. Based on theoretical incursions through Philosophy and Social Anthropology the concept of ethic-esthetic sense was made, as well as were extracted categories of analysis to the understanding this sense in popular culture through ethnographic-type developed study. This investigation indicates to a collective normatization process that generates own body techniques to the popular cultural groups, which are part of a complex relationship web.

Keywords: Ethic. Esthetic. Body. Dancing. Cultural diversity.
\end{abstract}

El sentido ético-estético del cuerpo en la cultura popular y la estruturación del campo gestual

Resumen: El texto analiza la construcción del sentido ético-estético del cuerpo en la cultura popular, trayendo subsidios para reflexiones sobre la estructuración del campo gestual. Por intermedio de incursiones teóricas por la Filosofía y por la Antropología Social el concepto de sentido éticoestético fue elaborado, así como fueran extraídas categorías de análisis para el entendimiento de ese sentido en la cultura popular a partir de pesquisa del tipo etnográfico. Las investigaciones apuntan para el proceso de normatización colectiva que genera técnicas corporales propias a las comunidades de cultura popular, siendo parte de una red compleja de relaciones.

Palabras clave: Ética. Estética. Cuerpo. Danza. Diversidad cultural.

\title{
REFERÊNCIAS
}

ADORNO, Theodor; HORKHEIMER, Max. Dialética do esclarecimento: fragmentos filosóficos. Rio de Janeiro: Jorge Zahar, 1985.

ANDRADE, Mário de. Danças dramáticas do Brasil. São Paulo: Itatiaia, 1982.

Movimento, Porto Alegre, v. 13, n. 03, p. 111-129, setembro/dezembro de 2007. 
ANDRÉ, Marli Eliza D. A. de. Etnografia da prática escolar. 7. ed. Campinas, SP: Papirus, 1995. (Série Prática Pedagógica).

BOGDAN, Robert; BIKLEN, Sari Knopp. Investigação qualitativa em educação. Porto, LDA, 1994.

BORBA, Alfredo et al. Brincantes. Recife: Fundação de Cultura Cidade do Recife, 2000. (Coleção Malungo; v.3).

CASCUDO, Luís da Câmara. Dicionário do folclore brasileiro. 10. ed. São Paulo: Global, 2001.

CHAUÍ, Marilena. Conformismo e resistência: aspectos da cultura popular no Brasil. São Paulo: Brasiliense, 1995.

CHAUÍ, Marilena. Convite à filosofia. 12. ed. São Paulo: Ática, 2001.

DURKHEIM, Émile. As formas elementares de vida religiosa: o sistema totêmico na Austrália. São Paulo: Paulinas, 1989.

ELIADE, Mircea. Mitos, sonhos e mistérios. Lisboa: Ed. 70, 1989.

LARA, Larissa Michelle. O sentido ético-estético do corpo na cultura popular. 2004. 226 f. Tese (Doutorado em Educação) - Faculdade de Educação, UNICAMP, Campinas, 2004.

LÉVI-STRAUSS, Claude. As estruturas elementares do parentesco. Petrópolis: Vozes, 1982.

MAUSS, Marcel. Sociologia e antropologia. São Paulo: EPU, 1974.

ORTIZ, Renato. Mundialização e cultura. São Paulo: Brasiliense, 2000.

PEIXE, Guerra. Maracatus do Recife. São Paulo, Rio de Janeiro: Irmãos Vitali, 1980.

Movimento, Porto Alegre, v. 13, n. 03, p. 111-129, setembro/dezembro de 2007. 